\title{
LEITURAS DO PASSADO PELA FICÇÃO: UM OLHAR LITERÁRIO À COLONIZAÇÃO BRASILEIRA EM A MÃE DA MÃE DA SUA MÃE E SUAS FILHAS (2002)
}

\section{READINGS OF THE PAST BY FICTION: A LITERARY VIEW OF THE BRAZILIAN COLONIZATION IN THE NOVEL $A$ MÃE DA MÃE DA SUA MÃE E SUAS FILHAS (2002)}

\author{
Patrícia de Oliveira ${ }^{1}$ \\ Gilmei Francisco Fleck ${ }^{2}$
}

\begin{abstract}
Resumo: Este estudo apresenta uma análise do romance brasileiro A mãe da mãe da sua mãe e suas filhas (2002), de Maria José Silveira. A obra aborda a história de uma família durante vinte gerações. O foco está nas personagens femininas que representam o "olhar visto de baixo", daqueles que viveram muitos acontecimentos históricos, mas tiveram suas vozes caladas nos registrtos oficiais. Nossa intenção é refletir sobre o processo de leitura de romances históricos no contexto do Ensino Fundamental II, séries finais, e Ensino Médio, pela introdução, neste contexto escolar, da modalidade mais recente do gênero híbrido de história e ficção proposto por Fleck (2017): o romance histórico contemporâneo de mediação. Desse modo, embasamo-nos, primeiramente, nos estudos sobre a leitura e sua importância no contexto escolar, valendo-nos de pressupostos de Lajolo (1993), Zilbermann (2004), Silva (2005), Martins (2005), entre outros. Em seguida, voltamo-nos ao gênero híbrido romance histórico, com suporte nos pressupostos de Weinhardt (1994; 2011), Fleck (2017), entre outros, para evidenciar aspectos formais da obra de Silveira (2002) e, em especial, para identificá-la como um romance histórico contemporâneo de mediação. Cremos que esta modalidade pode contribuir decisivamente para a formação de um leitor mais consciente na escola.
\end{abstract}

Palavras-chave: romance histórico contemporâneo de mediação; A mãe da mãe da sua mãe e suas filhas (2002); colonização brasileira; literatura comparada; romance histórico brasileiro.

\footnotetext{
1 Mestranda em Letras pelo Programa de Pós-graduação da UnioestelCascavel-PR, na linha de pesquisa: Linguagem Literária e Interfaces Sociais. Atua como professora de Língua Portuguesa no Ensino Fundamental e Médio no Estado do Paraná e integra a equipe de pesquisadores do Grupo de pesquisa "Ressignificações do passado na América: processos de leitura, escrita e tradução de gêneros híbridos de história e ficção - vias para a descolonização", cadastrado na Capes. E-mail: pat.oliveirah@gmail.com

${ }^{2}$ Pós-doutorado (2015) em Literatura Comparada e Tradução pela Universidade de Vigo, com Bolsa da CAPES. Atualmente, é Professor Associado da UnioestelCascavel-PR, atuando na Graduação em Letras, nas áreas de Literatura e Cultura Hispânicas, e na Pós-Graduação em Letras (Mestrado Acadêmico e Doutorado), nas áreas de Literatura Comparada e Tradução. No Mestrado Profissional (Profletras), atua como coordenador do Programa (2018-2020) e como docente na área da Literatura Infantil e juvenil. É coordenador do PELCA: Programa de Ensino de Literatura e Cultura-PROEX/Unioeste-Cascavel. É líder do Grupo de Pesquisa "Ressignificações do passado na América: processos de leitura, escrita e tradução de gêneros híbridos de história e ficção - vias para a descolonização", cadastrado na CAPES. E-mail: chicofleck@yahoo.com.br
} 
Abstract: This text presents an analysis of the Brazilian historical novel A mãe da mãe da sua mãe e suas filhas (2002), by Maria José Silveira. This novel approaches the story of a family along 20 generations. The focus is put upon the feminine characters once they represent the "view from below", concerning those people who lived lots of the historical events but their voices remained silent in the official registers. Our intention is to reflect about the process of reading historical novels in the context of the final years of the Elementary school and also at High school. This could be done by introducing in this context the latest modality of this hybrid literary gender which classification was proposed by Fleck (2017) as the "contemporary historical novel of mediation". In this way we, firstly, approach the studies about reading and its importance in school contexts, by using the theories written by Lajolo (1993), Zilbermann (2004), Silva (2005), Martins (2005) and others. Then, following the course, we focus upon the historical novel, under the support of theories like the ones written by Weinhardt $(1994 ; 2011)$; Fleck (2017), and others, to evidence the formal aspects of Silveira's (2002) work and specially to identify her novel as a model of the contemporary historical novel of mediation. We believe that the reading of this modality of historical novels can decisively contribute to a more conscious reader at school.

Keywords: contemporary historical novel of mediation; $A$ mãe da mãe da sua mãe $e$ suas filhas (2002); brazilian colonization; compared literature; brazilian historical novels.

\section{Introdução}

O discurso historiográfico sobre a colonização da América Latina, especificamente no que tange às terras então lusitanas, apresenta uma visão ancorada no patriarcalismo a respeito da formação da sociedade que dará origem à nação brasileira. Há, nos registros oficiais desse passado, um grande destaque para a perspectiva do olhar masculino sobre as ações efetuadas por homens considerados heróis e modelos, e pouco enfoque há para a outra grande parcela do povo brasileiro, entre ela as mulheres, os negros, os indígenas e os mestiços aqui nascidos e responsáveis por inúmeros desdobramentos em nossa civilização.

Frente a essa realidade histórica e social de exclusões e apagamentos, na literatura atual de autoria feminina há uma procura pela representação daquilo que foram as condições da mulher nesse contexto. Tal ação escritural busca representar, de diversas maneiras, os problemas femininos, as condições em que ela se encontrava inserida nessa sociedade, a fim de questionar os estereótipos de submissão, herdados do patriarcalismo, e, também, para apontar a importância da mulher na sociedade.

Segundo Zolin (2009), as escritoras que emergem nesse contexto no qual há uma mudança significativa no papel social da mulher, propiciada pelo movimento feminista, 
"lançam-se no mundo da ficção, até então genuinamente masculino, engendrando narrativas povoadas de personagens femininas conscientes do estado de dependência e submissão a que a ideologia patriarcal relegou a mulher" (ZOLIN, 2009, p. 329).

Desse modo, novas possibilidades de conceber o passado são imaginadas na literatura e nela os sujeitos antes marginalizados e relegados à margem pela escrita histórica tradicional assumem um papel protagônico. Essa é uma das vertentes literárias que precisa adentrar o espaço institucional da escola para disseminar-se na sociedade atual para promover a descolonização das mentes, pois

[...] é à literatura, como linguagem e como instituição, que se confiam os diferentes imaginários, as diferentes sensibilidades, valores e comportamentos através dos quais uma sociedade expressa e discute, simbolicamente, seus impasses, seus desejos, suas utopias. Por isso a literatura é importante no currículo escolar: o cidadão, para exercer plenamente sua cidadania, precisa apossar-se da linguagem literária, alfabetizar-se nela, tornar-se seu usuário competente, mesmo que nunca vá escrever um livro. (LAJOLO, 1993, p. 106-107)

Pela pouca representatividade da mulher na escrita da história tradicional, é na literatura contemporânea que as personagens femininas, muitas de extração histórica, ganham voz para revelar suas ações e poder para transmitir o valor de seus feitos. Nas escritas híbridas de história e ficção, especialmente naquelas engendradas por mulheres, elas deixam as margem do sistema e passam a exercer o protagonismo para recontar ao leitor fatos do passado colonial, imperial e republicano que foram omitidos e não ganharam o devido destaque, pois os registros desse contingente possuíam uma visão periférica para assuntos que interessavam, primeiramente, à coroa portuguesa, depois, à burguesia imperial, e, por fim, à elite atual brasileira.

Neste cenário surgiu na Europa, no século XIX, o romance histórico, gênero literário híbrido que não se propõe unicamente a ideia de recontar a história sob outro viés, ou “[...] repetir o relato dos grandes acontecimentos, mas ressuscitar poeticamente os seres humanos que viveram essa experiência" (WEINHARDT, 1994, p. 51).

Esse gênero literário híbrido permitiu à literatura, com a evolução de sua trajetória, uma revisitação consciente ao passado e, consequentemente, o preenchimento de lacunas deixadas pela escrita da historiografia tradicional que, naquela época de nossa colonização, 
por exemplo, apenas voltava-se às façanhas políticas e às ações conquistadoras dos "grandes heróis".

Tal ação crítica da literatura contemporânea possibilita ao leitor estabelecer um novo ângulo de visão às mazelas da sociedade que aqui começava a se formar com bases apoiadas no intenso processo de miscigenação racial empreendido pelos conquistadores. Isso ocorre porque tal vertente literária híbrida propicia uma análise mais multifacetada dos acontecimentos passados, relidos na escrita híbrida de história e ficção, para que o leitor tenha condições de ampliar suas possibilidades de imaginação sobre o que possa ter sido o passado.

Considerando que a leitura da palavra, conforme Freire (1982), é precedida pela leitura do mundo, o trabalho com a leitura, na escola, precisa pautar-se nas relações sociais contidas nas obras e que despertam as conexões com as experiências dos leitores. No romance histórico temos a representação de tais relações sociais vistas, muitas vezes, desde o ângulo dos excluídos, daqueles que, na escrita autorizada da história, foram silenciados.

Algumas das modalidades contemporâneas dessa escrita trazem a verossimilhança para o texto, enquanto outras, mais críticas e desconstrucionista, buscam empregar meios escriturais que revelam sem escrúpulos que história e literatura nada mais são do que construtos linguísticos e que, como frutos da linguagem, são claramente manipuláveis.

As modalidades menos desconstrucionistas do romance histórico são leituras possíveis de serem realizadas com alunos das séries finais do Ensino Fundamental e, com certeza, com aqueles do Ensino Médio. Nessas representações vemos um apelo à verossimilhança, elas mantêm a linearidade cronológica dos eventos relidos pela ficção, porém efetuam a manipulação temporal da narrativa, com certas analepses e prolepses, dão voz àquelas personagens postas às margens nos registros oficiais, e não mais aos consagrados heróis históricos.

Assim, tais leituras se aproximam, também, dos pressupostos críticos das releituras da história pela ficção, que fundamentam as produções mais atuais do gênero. São escritas que empregam uma linguagem mais fluída; valendo-se da intertextualidade e de outras estratégias para reler, de forma crítica, o passado histórico pela ficção. É por essas características, entre outras, que defendemos a necessidade de que professores e alunos comecem a ter acesso a essas leituras na trajetória da formação do leitor na escola e na vida. 


\section{0 romance histórico e sua leitura na escola: uma experiência conscientizadora}

Somente a leitura, entendida como uma atividade social e reflexiva - cujos objetos não devem ficar atrelados apenas à tradição - pode propiciar uma relação criativa, crítica e libertadora com a escrita - capacidade na qual se revela, em potencial, o poder da palavra na construção ideológica, discursiva e argumentativa. Esse conhecimento - ensinado e aprendido - mostra-se como um desafio para qualquer processo de democratização e transformação social coletivo.

Ao fazer-se da leitura uma prática essencial do Ensino Fundamental e Médio ancorada no próprio processo evolutivos das escritas endereçadas aos estudantes - estaremos formando cidadãos mais plenos e conscientes de sua atuação como agentes históricos. Ao reivindicarmos do poder vigente as condições para tal ensino na escola, exercitamos nossa cidadania, pois nessa prática se incluem diretos e deveres essenciais do cidadão e do governo.

Zilbermann (2004) chama atenção para a leitura literária como modalidade de educação e esclarece que, na trajetória do ensino da Literatura, por muitos séculos, o conhecimento dos clássicos e do cânone consagrado foram privilegiados, mas, nas últimas décadas, “[...] primeiro jogou-se ao mar a carga da história; depois, foi abandonada a própria literatura, desfeita na definição imprecisa de texto" (ZILBERMANN, 2004, p. 18). Ela explica:

[...] essas opções decorreram de um processo, ele mesmo, histórico, relacionado à ascensão à escola pelas classes populares, que, assim, permanecem alienadas da tradição e do passado, ao qual podem não pertencer, com o qual podem não se identificar, mas que se relaciona à formação da identidade nacional, com a qual devem interagir, seja para aceitá-la, seja para contrariá-la. (ZILBERMANN, 2004, p. 18)

A história de nosso país, inalteradamente, segue revelando que "ler continua sendo coisa das elites, no início de um novo milênio" (ROJO, p. 1, 2014). Como poder concentrado nas camadas elitizadas, o conhecimento do ato de ler e, em consequência o de escrever, estabelece os limites que interpolam a estratificação social.

É o aprendizado efetivo da leitura que pode ajudar a desnudar cenários de desigualdade na sociedade. Por meio dele pode-se ter a possibilidade de galgar degraus na 
escada social imposta por uma sociedade estratificada de acordo com as possibilidades materiais de cada um. Ao considerar esse papel crítico da leitura, Soares (2005) salienta que

[...] o acesso ao conhecimento diferenciado, aquele que permite ao leitor reconhecer sua identidade, seu lugar social, as tensões que animam o contexto em que vive ou sobrevive, e, sobretudo, a compreensão, assimilação e questionamento seja da própria escrita, seja do real em que a própria escrita se inscreve (Osakabe, 1982), o domínio da leitura assim entendida é ameaça à dominação, por isso negado às camadas populares. (SOARES, 2005, p. 25)

O texto literário é, sem dúvidas, o espaço no qual "o contexto em que vive ou sobrevive" o sujeito brasileiro melhor encontra-se representado em toda a sua gama de multiplicidades, desigualdades e contrastes. Nesse sentido, o romance histórico e suas propostas de releitura críticas de diferentes fatos históricos nos permite compreendê-lo como importante ação descolonizadora, pois possibilita a análise de fatos consagrados nos anais da historiografia, a fim de reafirmar e/ou refutar as versões perpetradas por essa linha de discursos sobre o passado.

A escrita desse gênero é mutável e reinventável em conformidade com os objetivos almejados pelo escritor, pela ideologia reinante no lócus enunciativo e, também, na compreensão e construção de um sujeito leitor mais crítico.

À escola cabe, por excelência, o papel de formar leitores capacitados para estabelecer a leitura crítica do mundo. A sociedade pode e deve participar dessa tarefa. Contudo, é no espaço institucional da escola onde o processo de leitura precisa ser instaurado e conduzido para transformar-se em um ato crítico de reflexão. Tal processo deve acompanhar todas as etapas escolares de formação do sujeito. Conforme defende Silva (2003, p. 16),

[...] a leitura - como atividade vinculada à consciência crítica do mundo, do contexto histórico-social em que o aluno está inserido - precisa ser praticada em sala de aula. O papel da escola é o de formar leitores críticos e autônomos capazes de desenvolver uma leitura crítica do mundo. Contudo, esta noção parece perder-se diante de outras concepções que ainda orientam as práticas escolares.

É, pois, nas práticas escolares que leituras descolonizadoras precisam começar a encontrar espaço de discussão e efetivação. Experiências de leitura do romance histórico com alunos das séries finais do Ensino Fundamental II já foram realizadas e, segundo os registros dos pesquisadores, a prática revela-se frutífera e possível. 
Uma das experiências realizadas neste campo da formação conscientizadora de leitores no âmbito escolar foi efetuada pela professora Rosmere Vivian Adriana Ottonelli ${ }^{3}$, no contexto do Programa de Pós-graduação Profissional em Letras - Profletras, em uma escola pública do Estado do Paraná. Na referida pesquisa, especialmente em sua dimensão prática pedagógica, leituras interdisciplinares sobre a Guerra do Paraguai (1864-1870), foram selecionadas e levadas à sala de aula, num projeto de leitura literária com uma turma do $9^{\circ}$ ano. Sobre os resultados, a pesquisadora expressa:

\begin{abstract}
A seleção do corpus mostrou-se adequada ao ano escolar e faixa etária dos educandos com os quais trabalhamos, e auxiliou na dinâmica das leituras. Tanto os romances pertencentes ao gênero novo romance histórico latino-americano, quanto os classificados como romances históricos de mediação foram efetivos na proposta, pois os educandos conseguiram efetivar a leitura no tempo estipulado e não demonstraram dificuldade de entendimento, o que observamos durante as discussões e comparações com os filmes e o texto didático. Os demais itens do corpus também se mostraram acessíveis à proposta. (OTTONELLI, 2015, p. 119)
\end{abstract}

A complexidade, tanto na linguagem quanto nas estruturas experimentais, dos primeiros romances históricos críticos produzidos na América Latina afastaram esse gênero do espaço das salas de aula do Ensino Fundamental e Médio. A constante evolução do gênero, contudo, fez surgir, com mais frequência, a partir da década de 1980, uma modalidade menos experimentalista, cuja produção se ancora na incorporação de algumas características das primeiras modalidades acríticas do gênero - como a linearidade narrativa e o uso de uma linguagem amena e coloquial - com outras específicas das modalidades críticas - entre elas a releitura do passado sob perspectivas marginalizadas, ancoradas na paródia, na intertextualidade e na polifonia. Esses são os romances de mediação, cujo teor crítico revela outras possibilidades de revisitar o passado.

Sobre a leitura dessa modalidade específica do romance histórico com alunos do Ensino Fundamental II, anos finais, Ottonelli (2015, p. 119) esclarece:

Em especial sobre os romances históricos de mediação (FLECK, 2008, 2011) Ana Néri, a brasileira que venceu a guerra, de Louzeiro (2002), e Adeus, chamigo brasileiro, de Toral (1999), podemos afirmar que a receptividade foi maior, pois

\footnotetext{
${ }^{3}$ Os registros encontram-se na dissertação Leituras entre a ficção e a história no contexto escolar: caminhos da transdisciplinaridade com perspectivas da Guerra do Paraguai (1864-1870), defendida no ano de 2015. Dados específicos encontram-se nas referências.
} 
mais educandos as leram em relação aos demais romances. [...]. Com o enfoque aos heróis sob um aspecto mais humanizado, e também aos anônimos, aos quais a Literatura dá voz, pudemos enfatizar os fatos históricos sob uma perspectiva diferente daquelas com as quais os educandos estão habituados. (OTTONELLI, 2015, p. 119)

Os acontecimentos históricos relatados e relidos pela ficção nos possibilitam imaginar diferentes perspectivas sobre os eventos, visto que o discurso historiográfico apresenta apenas a visão daqueles que detinham o poder. Pelo olhar literário é possível verificar as diferentes e possíveis visões desses fatos, incluindo, nessas recriações imaginárias, a percepção dos marginalizados e excluídos da sociedade.

Nesse gênero híbrido, o fato histórico não é apenas um detalhe narrativo, mas, sim, um importante elemento para (des)construção do discurso unívoco já posto e oficializado na historiografia. Isso, seguramente, não altera o passado, porém pode possibilitar que o leitor desenvolva um pensamento crítico frente àquelas "verdades" disseminadas pelos que detinham o poder e, assim, começar, na atualidade, um processo de descolonização ainda necessário em nossa sociedade.

Tais experiências de leitura levadas à prática na sala de aula nos mostram que já é hora de desmistificar a aura sagrada do texto literário e torna-lo, pela mediação comprometida e eficiente do professor, acessível ao aluno já no Ensino Fundamental. Podemos, assim, repensar a questão de que

[...] na escola, diante da imposição das leituras idealizadas pelos professores e pelos livros didáticos, constrói-se o mito de que a leitura literária é difícil, complexa e inacessível para os alunos, subestimando-se a capacidade interpretativa dos educandos. Soma-se a isso o fato de a escola enfatiza a leitura dos textos clássicos, com o objetivo de, à primeira vista, "facilitar" o contato do aluno com obras canônicas para depois desenvolver a leitura de textos mais contemporâneos e experimentais. (MARTINS, 2005, p. 17)

Embora não empreendam a desconstrução de grandes heróis do passado, as narrativas mediativas do romance histórico contemporâneo de mediação - com um discurso que se constrói entre a tradição e a desconstrução - deixam seus reflexos críticos sobre a história tradicional e a própria literatura brasileira muitas vezes acrítica em relação à colonização e sua persistência nas antigas colônias europeias. Lajolo (2004), cujos estudos também se 
voltam para o romance brasileiro, sobre o gênero romance histórico, tece a seguinte consideração:

Talvez um dos segredos do sucesso dos romances que se inspiram na história seja que eles dão dimensão cotidiana a personagens heroicas (sic). Os grandes vultos nacionais - para além da aura de heroísmo que os distingue - geralmente têm um perfil magro e seco esculpido por sisudos livros escolares. Nomes de ruas e estátuas de praças públicas, quando emigram para enredos de romances, retocam este perfil descarnado, permitindo ao leitor momentos de aproximação com heróis e figuras célebres. (LAJOLO, 2004, p. 116)

Desse modo, o espaço da sala de aula do Ensino Fundamental e Médio tem se mostrado receptivo e propício às leituras críticas do passado pela ficção quando o processo inicia-se pela modalidade mediativa do gênero. Muitas são as obras atuais que se inserem neste contexto de produção. Destacamos, para alguns comentários, na sequência deste texto, o romance A mãe da mãe da sua mãe e suas filhas (2002), de Maria José Silveira.

\section{A mãe da mãe da sua mãe e suas filhas (2002): uma história entre mulheres}

Ao ler o romance A mãe da mãe da sua mãe e suas filhas (2002) é possível verificar, na diegese proposta, o entrecruzamento entre história e ficção desde as suas primeiras páginas. Isso permite ao leitor uma aproximação ao texto que fica no limiar das duas áreas. Tal peculiaridade na tessitura escritural gera um processo de leitura na qual enfrentamentos entre o conhecimento geral da história, que foi transmitida nas instituições culturais, confronte-se com visões diferenciadas e perspectivas inusitadas, dadas pela ficção à contemplação dos eventos.

Vemos, assim, já no começo da leitura, que

[...] a narrativa histórica se constrói sobre fatos reais, a narrativa ficcional sobre fatos imaginários, mas as duas são construções verbais. Quanto ao caráter de ambas enquanto construções verbais, não há o que questionar. Mas no caso da ficção de caráter histórico, também a distinção de conteúdo tende a se atenuar e até a desaparecer de vez, a ponto de muitas vezes o leitor comprometido com catalogações hesitar, se lhe exigem uma resposta imediata à pergunta se está lendo ficção ou história. (WEINHARDT, 2011, p. 14) 
Maria José Silveira (2002), ao ficcionalizar, na obra A mãe da mãe da sua mãe e suas filhas, a história de 500 anos de Brasil, pelo olhar da mulher brasileira, transmite aos leitores não só uma nova visão sobre a história, mas, também, expõem recursos para se compreender as diversas nuances possíveis da permanência dos traços de oralidade na formação do povo brasileiro.

Tal aspecto oriundo das tradições ancestrais dos povos nativos permite que raízes identitárias sejam revigoradas e brotem no discurso ficcional. Assim, outras vozes desse passado enclausurado em maniqueísmos e dicotomias tendenciosas dos registros historiográficos eurocêntricos chegam aos ouvidos dos leitores na atualidade.

Ao recriar os cenários de alguns momentos importantes do processo de formação do Brasil e da constituição de sua sociedade híbrida e mestiça, a autora aponta para alguns fatos da história oficial do país, trazendo para a obra representações de personagens verossímeis que poderiam ter vivido ao longo desses 500 anos e lhes dá o espaço da enunciação.

Nessa releitura do passado se incorpora, ainda, o processo de mestiçagem e as possíveis genealogias que foram surgindo ao longo da história brasileira, ancorada no evidente entrecruzamento racial das três etnias que estruturam nossa história social.

A trajetória imaginada para as personagens femininas do romance de Maria José Silveira (2002) contempla o panorama geral da história do Brasil, desde os primeiros passos da colonização até os eventos recentes do período republicano.

Alguns acontecimentos históricos são, nesse sentido, sutilmente mencionados no romance, enquanto outros são detalhados com riqueza e profundidade. Entre tais fatos aparecem, na diegese do romance, episódios como: o "descobrimento" do Brasil (1500); as missões jesuítas (1549), sutilmente mencionadas; os índios; instituição do governo geral no Brasil (1549); a escravização de índios e negros; a Guerra contra os holandeses (1630); derrota dos holandeses: primeira e segunda batalhas dos Guararapes (1648); a extração do ouro em Minas Gerais (1694); a Guerra dos Emboabas (1708); a invasão dos piratas franceses (1710-1711), apenas mencionada na obra; a Revolução Francesa (1789); a personagem Tiradentes (1792); recusa pernambucana (1817); a independência do Brasil (1822); a fuga de D. João e sua mãe, dona Maria, a rainha louca (1824); a Guerra do Paraguai (1864); a abolição da escravatura (1870-1888); a Lei Áurea (1888); Proclamação da República (1889); 
a Guerra de Canudos (1897); o governo de Getúlio (1930); a eleição de Juscelino Kubitschek (1955); O regime militar (1964); o período das Diretas já (1984); o Impeachament de Collor (1992), dentre outros.

A narradora de A mãe da mãe de sua mãe e suas filhas (2002) não participa da história como personagem das ações relatadas, mas tece comentários, desde seu tempo presente, em primeira pessoa (perspectiva autodiegética e voz heterodiegética), a respeito das personagens, épocas e ambientes do passado recriados no romance. Vejamos um fragmente desse discurso da narradora:

\footnotetext{
Está bem.

Se é assim que vocês querem, vamos contar a história das mulheres da família.

Mas vamos com calma.

O assunto é delicado, a família é complicada, e nem tudo foi beleza nesta história. Houve, claro, felicidades e amores, muitas lutas e conquistas, grandes realizações afinal, elas ajudaram a construir quase do nada este país. Mas houve também loucas, assassinas, muitas desgraças e tristezas. Grandes dores. Muitas mesmo.

Lembrem-se também, se for o caso, de que foram vocês que me pediram para contar, desta vez, a vida das mulheres. (SILVEIRA, 2002, p. 11).
}

Desse modo, na voz enunciadora do discurso do romance se revela a história linear da sua família, uma saga que é marcada pela oralidade. $\mathrm{O}$ assunto do relato são as histórias repassadas de mãe para filha que se tornaria, futuramente, mãe também e, desse modo, a trama familiar vai sempre ganhando novos capítulos, cenários, percalços e frutos para um país tão rico de raças e culturas familiares que se multiplicam e se misturam a cada página.

Com essa imagem introdutória do romance, a autora resgata a tradição ancestral das mulheres "contadoras de histórias" que tiveram suas vivências enunciadas no universo da cultura oral. Passar essa prática social ao universo da escrita - do romance histórico, em especial - é, assim, um ato de resistência, de consciência e de saber frente aos empecilhos que sempre estiveram postos à mulher nesse universo.

Assim, buscamos dedicar nossa atenção às histórias das personagens femininas elaboradas nessa tessitura discursiva, costuradas às tradições, e suas relações amorosas, de poder e de enfrentamentos, que trazem à trama todo um contexto histórico. Isso ocorre a partir de relatos e de personagens que garantem verossimilhança ao texto, explicitando, assim, uma das características que Fleck (2017) considera essenciais aos romances históricos contemporâneos de mediação: uma narrativa crítica sobre um evento do passado ancorada nas 
reais possibilidades de que ela poderia ter acontecido, na verossimilhança.

A narradora fornece aos leitores uma visão mais ampla do processo de construção do povo brasileiro a partir de recortes históricos e sociais específicos, acima mencionados, relatados a partir de dramas femininos, que não podem ser banalizados. A vivência verossímil dessas experiências remete o leitor a uma história que evidencia, também, a conquista do espaço da mulher na jornada que construiu as bases de uma nação mestiça e híbrida.

Assim, o romance gera um lócus enunciativo que possibilita essa voz manifestar-se e recuperar a memória de suas antepassadas, conforme se nota no princípio da narrativa, acima exposto, quando a voz enuncia: "Se é assim que vocês querem, vamos contar a história das mulheres da família [...] afinal, elas ajudaram a construir quase do nada este país" (SILVEIRA, 2002, p. 11). A linguagem é típica da interlocução de um evento de "contação de histórias" na qual o narrador se dirige aos ouvintes com o desafio da narração pela frente.

Esta voz narrativa que se manifesta ao longo de toda a diegese, embora rememore a existência de muitas mulheres, é única, fazendo com que o romance não seja pluriperspectivista, como é comum no novo romance histórico latino-americano e, desse modo, revela-se na escrita de Silveira (2002) outra das características comuns aos romances históricos contemporâneos de mediação: “embora o discurso se faça polifônico e dialógico, normalmente, a voz enunciadora do discurso é fixada pelo foco único, subjetivando o material histórico incluído na diegese." (FLECK, 2017, p. 110).

Nessa manifestação inicial da voz enunciadora do romance, fica explícito ao leitor o "olhar visto de baixo" (SHARPE, 1992) para o passado, para a história brasileira, para que revivamos e recriemos outra história tão mais presente e mais viva, capaz de incluir não apenas os "heróis", mas o contingente todo que, com seu esforço, construiu a nação.

A obra A mãe da mãe da sua mãe e suas filhas (2002) inicia sua trajetória de "evocar cenas de um passado de vivo colorido" com a aproximação do nascimento da personagem Inaiá (1500-1514), na região de Porto Seguro, Bahia, à medida que as caravelas portuguesas estão chegando: “À hora da véspera daquele 21 de abril, um monte alto e redondo foi avistado pelos marujos em rebuliço [...] no exato momento em que a mãe de Inaiá se dirigiu para o recanto da floresta que previamente escolhera para esse dia, [...].” (SILVEIRA, 2002, p. 18).

A autora faz uso das escritas primeiras da Carta de Achamento (1500), de Pero Vaz de Caminha em alguns trechos da obra, valendo-se da intertextualidade para criar uma maior 
verossimilhança na obra. No exato momento em que os portugueses lançam suas âncoras, nasce Inaiá. A personagem cresce de maneira concomitante ao desenrolar da colonização. Esta seria uma das primeiras autóctones a envolver-se com um conquistador português e iniciar a miscigenação racial, por meio de sua relação com a personagem Fernão, como podemos ler no extrato abaixo:

E quando o céu outra vez começou a escurecer e nos navios as âncoras foram lançadas e todos se ajoelharam para dar graças pela visão da floresta copada junto à estreita faixa de areia branca, as aves da beira do remanso se levantaram em revoada, assustadas como o primeiro choro de Inaiá. (SILVEIRA, 2002, p. 18)

A autora passa rapidamente pelos anos seguintes, dando maior enfoque para a relação entre portugueses e nativos pelo olhar de Inaiá, que cresce ao mesmo tempo em que sua terra é desmatada dia após dia. Quando jovem, a personagem Inaiá envolve-se com o português Fernão. Deste relacionamento nasce a mestiça Tebereté (1514-1548) e, assim, segue-se a trama linear com Sahy, (1531-1569), Filipa (1552-1584), Maria Cafuza (1579-1605), Maria Taiaôba (1605-1671), Belmira (1631-1658), Guilhermina (1648-1693), Ana de Pádua (16831730), Clara Joaquina (1711-1740), Jacira Antônia (1737-1812), Maria Bárbara (1773-1790), Damiana (1789-1822), Açucena Brasília/Antônia Carlota (1816-1906), Diana América (18461883), Diva Felícia (1876-1925), Ana Eulália (1906-1930), Rosa Alfonsina (1926-...), Lígia (1945- 1971), Maria Flor (1968-...).

Essa genealogia narra a história daquele que será o povo brasileiro, passando por diferentes espaços e eventos importantes, até chegar a época de 1968, na cidade do Rio de Janeiro, onde nasce Maria Flor, a última personagem da obra, mas não a última descendente desta árvore genealógica, pois, no presente da narrativa, ela já está grávida.

Já no primeiro episódio sobre Inaiá se manifesta a linguagem amena com a qual o romance se efetivará em toda sua extensão, atendendo a mais uma das principais características do romance histórico contemporâneo de mediação que "prima pelo emprego de uma linguagem simples e de uso cotidiano, em oposição ao barroquismo e ao experimentalismo linguístico dos novos romances históricos [...]” (FLECK, 2017, p. 110). Essa linguagem empregada pela escritora reflete com muita clareza o momento da enunciação, a temporalidade atual na qual está inserida a narradora "contadora de histórias". 
Desse modo, as 20 personagens femininas da narrativa de Silveira fazem o percurso da história geral do Brasil e podem ser uma alternativa para que os alunos do Ensino Fundamental II, séries finais e alunos do Ensino Médio possam confrontar-se com novas perspectivas de nosso passado. Está, assim, a disposição dos leitores uma nova visão centrada no olhar feminino - do passado do Brasil.

Aos professores isso se revela em um rico material para leitura e relações interdisciplinares nas práticas pedagógicas. Cada vida ficcionalmente criada pro Silveira é um modo peculiar de revistar o passado. Devemos, pois, abrir o romance, e nossas mentes, e iniciar o processo de leituraldescolonização.

\section{Considerações finais}

Incentivar, já nas séries finais do Ensino Fundamental, a leitura de obras híbridas de história e ficção dá um sentido mais amplo ao necessário processo de formação de leitores no espaço escolar. Ao desmitificar a "dificuldade" da leitura do texto literário junto aos alunos, tais textos promovem, além do prazer no ato de ler - pois é bem comum que o leitor juvenil já tenha conhecimento básico sobre os acontecimentos históricos ficcionalizados no romance um envolvimento emocional e conscientizador do aluno com fatos do passado que, na maioria das vezes, são conhecidos apenas pelo viés da historiografia hegemônica.

As modalidades críticas de romances históricos são de grande importância para a conscientização de como os fatos ocorridos na América Latina repercutiram na escrita histórica, contribuindo para a formação crítica individual e coletiva no imaginário das pessoas.

Tal escrita trata-se de uma importante possibilidade para a contestação da tradição histórica europeia no ambiente colonizado da América Latina. O romance histórico latinoamericano, ao voltar-se para o passado histórico, escrito e oral, busca compreender como os povos subjugados foram retratados e, então, contesta a historiografia desde a perspectiva dos colonizados, como ocorre com as personagens femininas do romance de Silveira (2002).

Fica, assim, aos professores o desafio de incorporar essas leituras em suas propostas pessoais e, posteriormente, nas práticas pedagógicas junto aos alunos com os quais estão diariamente em contato. 


\section{Referências}

FLECK, G. F. O romance contemporâneo de mediação: entre a tradição e o desconstrucionismo - releituras críticas da história pela ficção. Curitiba: CRV, 2017.

LAJOLO, M. No mundo da leitura para a leitura do mundo. São Paulo, SP: Ática, 1993.

MARTINS, I. Literatura em sala de aula: da teoria literária à prática escolar Recife: Programa de Pós-Graduação em Letras da UFPE (2005).

OTTONELLI, R. A. V. Leituras entre a ficção e a história no contexto escolar: caminhos da transdisciplinaridade com perspectivas da Guerra do Paraguai (1864-1870). 2015. (150 páginas). Dissertação (Mestrado Profissional em Letras) - Universidade Estadual do Oeste do Paraná - UNIOESTE, Cascavel, 2015.

SHARPE, J. A história vista de baixo. In: BURKE, P. (Org.). A escrita da história: novas perspectivas. Tradução : Magda Lopes. São Paulo: UNESP, 1992. p. 39-62.

SILVEIRA, M. J. A mãe da mãe da sua mãe e suas filhas. São Paulo: Globo, 2002.

SILVA, E. T. Elementos de pedagogia da leitura: São Paulo: Martins Fontes. trilogia pedagógica. Campinas: Autores Associados, 2003.

SOARES, M. Linguagem e escola: uma perspectiva social. 17.ed. São Paulo: Ática, 2005.

WEINHARDT, M. Considerações sobre o romance histórico. Curitiba: Revista Letras, v. 43, p. 49-59, 1994.

WEINHARDT, M. Ficção histórica: teoria e crítica. Ponta Grossa: UEPG, 2011.

ZOLIN, L, O. Crítica feminista. In: BONNICI, T.; ZOLIN, L. O. (ORG.). Teoria literária: abordagens históricas e tendências contemporâneas. 3. ed. Maringá: Eduem, 2009. p. 217242.

Recebido em 20 de janeiro de 2019. Aceito para publicação em 25 de maio de 2019. 